\title{
Frequency of Thyroid Lesions on Fine Needle Aspiration Cytology in Different Age Groups: A Teaching Hospital-Based Study
}

\author{
Asma Kalim ${ }^{1}$ \\ ${ }^{1}$ Assistant Professor, Department of Pathology, Narayan Medical College and Hospital, Sasaram, Jamuhar, Bihar, India.
}

\section{Abstract}

Background: Thyroid Fine Needle Aspiration Cytology (FNAC) was introduced in Scandinavian countries in 1950s and became popular in the United States in 1970s and then worldwide in the 1980s. Subjects and Methods: A total of 129 patients with thyroid nodules were enrolled after fulfilling these inclusion \& exclusion criteria and were sent for FNAC. Total of 129 patients presented with thyroid swelling were assessed clinically, along with laboratory investigations like thyroid function tests, ultrasonography and by FNAC study. Results: Nodular goiter was the commonest-34 (26.3\%), colloid goiter- $13(10.1 \%)$, nodular goiter with cystic change- 11(8.5\%), thyroid cyst- 10(7.75\%), nodular goitre with hyperplasia- 3 (2.3\%). Hashimoto's thyroiditis accounted for 45(34.9\%), papillary carcinoma and papillary carcinoma with Hashimoto's thyroiditis- 6(4.6\%), diffuse hyperplasia- 2(1.55\%), lymphocytic thyroiditis- 2(1.55\%), follicular neoplasm- 1(0.77\%). Conclusion: The wide range of lesions, both benign and malignant, can be diagnosed by FNAC thus restricting surgery to cases only requiring further histopathological evaluation. Nodular goiter $(26.3 \%)$ is the foremost commonest cause of thyroid enlargement followed by Hashimoto's thyroiditis.

Keywords: Thyroid lesions, Frequency and FNAC.

Corresponding Author: Dr. Asma Kalim, Assistant Professor, Department of Pathology, Narayan Medical College and Hospital, Sasaram, Jamuhar, Bihar, India.

Received: January 2019

Accepted: February 2019

\section{Introduction}

Thyroid Fine Needle Aspiration Cytology (FNAC) was introduced in Scandinavian countries in 1950s and became popular in the United States in 1970s and then worldwide in the 1980s. ${ }^{[1]}$ Today it remains the mainstay of diagnostic workup for thyroid pathologies. Thyroid FNA is a safe and relatively simple test that is widely recognized as the critical, primary diagnostic procedure of first choice for the evaluation of patients presenting with thyroid nodules. ${ }^{[2-5]}$ One of the major advantages is that FNAC can be done as an out-patient procedure. Neck swelling is a common clinical presentation all over the world. Thyroid gland enlargement is a common presentation in the general population and in the FNAC OPD, but all thyroid enlargements do not require surgery. ${ }^{[6]}$ Thyroid nodules are common but thyroid cancer is uncommon. ${ }^{[7]}$ FNAC is a very useful modality to decide on the patients requiring surgery from those who need not be operated. ${ }^{[8]}$ Introduction of FNAC in the field of thyroid diagnostic tests has reduced thyroid surgeries considerably. ${ }^{[9]}$ The main requirement for thyroid FNAC is to differentiate neoplastic from non neoplastic lesions and get a definite diagnosis of the enlargement. ${ }^{[10]}$ FNAC is usually the first line of investigation followed by ultrasound examination, thyroid function tests and antibody levels. ${ }^{[1]}$ FNAC is widely accepted as the most cost-effective diagnostic procedure in the assessment of thyroid nodules and also helps to select patients preoperatively for surgery. ${ }^{[12]}$ Aim of this present study was to distribution of various thyroid lesions on fine needle aspiration cytology in different age groups.

\section{Subjects and Methods}

This present study was conducted in the Department of Pathology, Narayan Medical College and Hospital, Sasaram, Jamuhar, Bihar, India. Patients presented with thyroid swelling to the OPD of Narayan Medical College and Hospital, India was included in the present study over a period of one year from September 2017 to November 2018. A total of 129 patients with thyroid nodules were enrolled after fulfilling these inclusion \& exclusion criteria and were sent for FNAC. Total of 129 patients presented with thyroid swelling were assessed clinically, along with laboratory investigations like thyroid function tests, ultrasonography and by FNAC study. Patients presenting with Thyroid swelling of all age and sex groups were included in the study. A detailed history pertaining to neck swelling and relevant questions pertaining to the etiological factors, duration, symptoms of hypothyroidism or hyperthyroidism, previous surgery were elicited from all the patients. Patients were examined clinically for thyroid swelling; following features were noted like size of thyroid gland, type of enlargement (diffuse/nodular), consistency (firm/soft), and movement on deglutition and protrusion of tongue and any associated cervical lymph node 
enlargement. The cases were thoroughly interrogated, clinically examined and relevant investigations done. FNAC procedure was explained to the patient and patient was placed in a comfortable position. They were then subjected to fine needle aspiration cytology. Aspirations were carried out with 23 or 24 gauge needles of varying lengths with 10 $\mathrm{ml}$ syringes and the material obtained. The aspirated material was expelled on the glass slides, smears were made, slides were air dried and stained by Giemsa stain, and also the remaining slides were fixed in alcohol, then stained with haematoxylin and Eosin stain for evaluation in each case. In fluid aspirates, material was centrifuged and slide was prepared with the sediment. Aspiration was done at 2-3 sites and in some suspicious cases and elderly patients, USG guided FNAC was done. In 15 cases where aspirate was unsatisfactory, repeat FNAC under USG guidance yielded adequate material. For all cases of solitary thyroid nodule, either solid or cystic USG examination was done mandatorily in order to get satisfactory material and not to miss cystic papillary carcinoma.

\section{Results \& Discussion}

The age of the patients varied between 7 and 74 years, the mean age being 37 years. One Hundred and fifteen cases were female $(89.14 \%)$ and 14 cases were male $(10.85 \%)$. Among the diagnostic outcome, 119 (92.24\%) were Benign (non-neoplastic), 8(6.20\%) were malignant \& 2 (1.5\%) were inconclusive. Nodular goiter was the commonest-34 $(26.3 \%)$, colloid goiter- $13(10.1 \%)$, nodular goiter with cystic change- $11(8.5 \%)$, thyroid cyst- $10(7.75 \%)$, nodular goitre with hyperplasia- 3 (2.3\%). Hashimoto's thyroiditis accounted for 45(34.9\%), papillary carcinoma and papillary carcinoma with Hashimoto's thyroiditis- 6(4.6\%), diffuse hyperplasia- $2(1.55 \%)$, lymphocytic thyroiditis- $2(1.55 \%)$, follicular neoplasm- 1(0.77\%) [Figure 1]. FNAC is not a substitute for conventional surgical histopathology, it is regarded as an extremely valuable complement in diagnosis and it is becoming just as indispensable. ${ }^{[13]}$ The FNAC procedure is performed without local anesthesia with the help of the non-aspiration technique, using 23 or 24 gauge needles. ${ }^{[14]}$

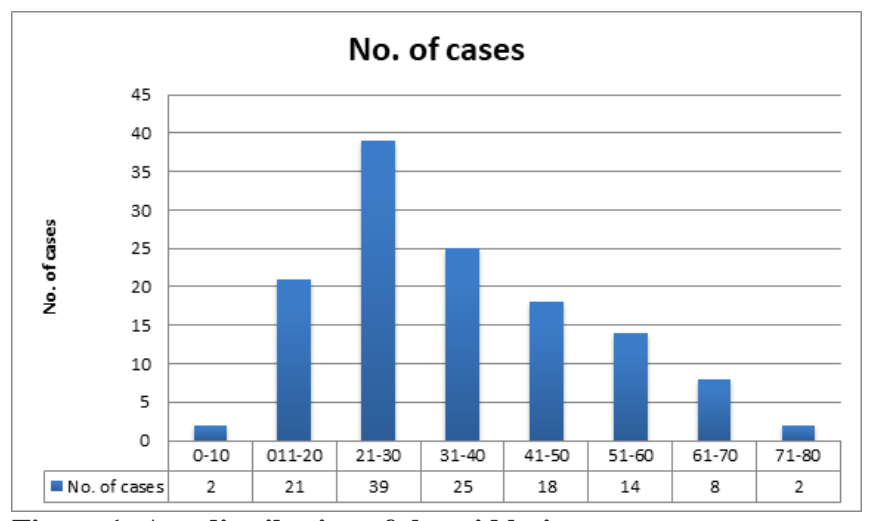

Figure 1: Age distribution of thyroid lesions

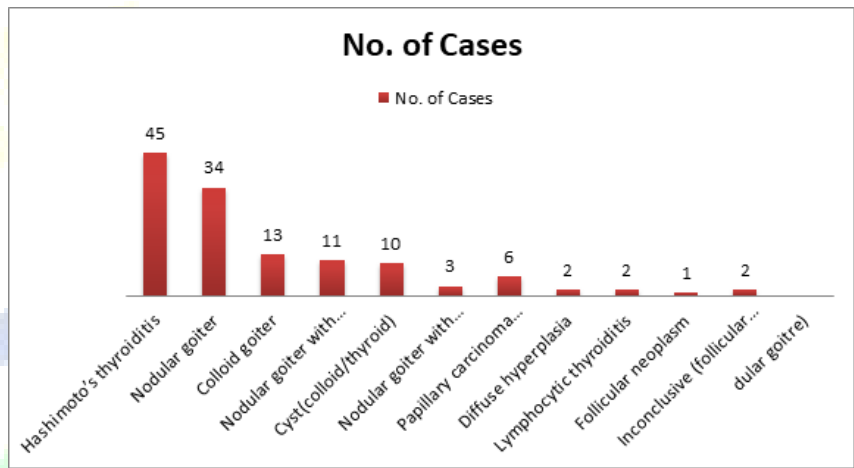

Figure 2: Prevalence of various thyroid lesions.

Table 1: Frequency of thyroid lesions in various age groups.

\begin{tabular}{|c|c|c|c|c|c|c|c|c|c|}
\hline Diagnosis & $0-10$ & $11-20$ & $21-30$ & $31-40$ & $41-50$ & $51-60$ & 61-70 & $70-80$ & Total \\
\hline Nodular goiter & $0(00)$ & $6(17.6)$ & $13(38.2)$ & $8(23.5)$ & $4(11.8)$ & $1(2.9)$ & $2(5.9)$ & $0(00)$ & $34(26.3)$ \\
\hline Hashimoto's hyroiditis & $0(00)$ & $4(8.9)$ & $10(22.2)$ & $19(42.2)$ & $6(13.3)$ & $3(6.7)$ & $2(4.4)$ & $1(2.2)$ & $45(34.9)$ \\
\hline Colloid goiter & $0(00)$ & $5(38.5)$ & $3(23.07)$ & $2(15.4)$ & $1(7.7)$ & $1(7.7)$ & $1(7.7)$ & $0(00)$ & $13(10.1)$ \\
\hline $\begin{array}{l}\text { Nodular goiter with } \\
\text { cystic change }\end{array}$ & $0(00)$ & $1(9.09)$ & $2(18.2)$ & $3(27.3)$ & $4(36.4)$ & $1(9.09)$ & $0(00)$ & $0(00)$ & $11(8.5)$ \\
\hline Cyst(colloid/thyroid) & $1(10.0)$ & $2(20.0)$ & $3(30.0)$ & $2(20.0)$ & $1(10.0)$ & $1(10.0)$ & $0(00)$ & $0(00)$ & $10(7.7)$ \\
\hline Diffuse hyperplasia & $0(00)$ & $0(00)$ & $1(50.0)$ & $1(50.0)$ & $0(00)$ & $0(00)$ & $0(00)$ & $0(00)$ & $2(1.5)$ \\
\hline $\begin{array}{l}\text { Nodular goiter with } \\
\text { hyperplasia }\end{array}$ & $0(00)$ & $0(00)$ & $1(33.3)$ & $1(33.3)$ & $1(33.3)$ & $0(00)$ & $0(00)$ & $0(00)$ & $3(2.3)$ \\
\hline $\begin{array}{l}\text { Lymphocytic } \\
\text { thyroiditis }\end{array}$ & $0(00)$ & $0(00)$ & $1(50.0)$ & $0(00)$ & $0(00)$ & $1(50.0)$ & $0(00)$ & $0(00)$ & $2(2.3)$ \\
\hline Papillary carcinoma & $0(00)$ & $0(00)$ & $1(20.0)$ & $2(40.0)$ & $1(20.0)$ & $1(20.0)$ & $0(00)$ & $0(00)$ & $5(3.9)$ \\
\hline $\begin{array}{l}\text { Hashimoto's with } \\
\text { papillary carcinoma }\end{array}$ & $0(00)$ & $0(00)$ & $1((100.0)$ & $0(00)$ & $0(00)$ & $0(00)$ & $0(00)$ & $0(00)$ & $1(0.77)$ \\
\hline Follicular/nodular & $0(00)$ & $0(00)$ & $1(50.0)$ & $1(50.0)$ & $0(00)$ & $0(00)$ & $0(00)$ & $0(00)$ & $2(2.3)$ \\
\hline Follicular neoplasm & $0(00)$ & $0(00)$ & $0(00)$ & $0(00)$ & $0(00)$ & $0(00)$ & $1(100.0)$ & $0(00)$ & $1(0.77)$ \\
\hline Total & $1(0.77)$ & $18(13.9)$ & $37(28.7)$ & $39(30.2)$ & $18(13.9)$ & $9(6.9)$ & $6(4.6)$ & $1(0.77)$ & 129 \\
\hline
\end{tabular}

In all cases, first FNAC was done by non-aspiration technique. In lesions of colloid goiter, nodular goiter, hyperplasia and neoplasia adequate aspirate was obtained. In those cases where adequate aspirate was not obtained by non-aspiration technique, then negative suction was given with a syringe and aspiration was done. This was usually needed in cases of Hashimoto's thyroiditis. This can be explained due to the solidification of the thyroid tissue by 
the dense lymphocytic infiltration and reduced vascularity when compared to the other thyroid lesions. The false negative FNAC results may occur because of sampling error ${ }^{[15]}$ Inadequate sampling is seen with inexperience of the cytopathologists, may also often results from sclerotic calcified nodules, nodules with cystic degeneration and calcified nodules. ${ }^{[14,16]}$ In a study of 514 patients by Filip Gabalec et al, a change from benign results to suspicious/ malignant in $13 \%$ of cases was seen on repeat FNAC. Repeating FNAC in patients with benign cytology in about one year horizon can reduce the rate of undiagnosed tumors. ${ }^{[17]}$ FNAC can be performed with or without ultrasound guidance but diagnostic accuracy improved with sonographic needle localization due to decreased number of inadequate specimens and false negative results. ${ }^{[18]}$ In the thyroid glands with multiple nodules, each nodule can vary in the cytological appearance and one of them could be neoplastic. In such cases, USG guided FNAC is very useful in determining the area and nodule to be aspirated which is suspicious of neoplasms. In our study, aspirates negative for cells (unsatisfactory aspirates) underwent ultrasound guided FNAC and good aspirates were obtained in most of the cases. Many a times, on blind FNAC neoplasms are missed due to sampling errors and on subsequent thyroidectomy, follicular and papillary neoplasms were identified. This can be minimised by guided FNAC. The ultrasound features of thyroid malignancy includes irregular edges, solid lesion, hypoechogenicity and being a single nodule respectively. ${ }^{[19]}$ Thyroid nodule size must not be considered as a criteria for malignancy and thyroid nodule of any size may be suspected malignant. ${ }^{[19]}$ False negative rate can be reduced by repeating the FNAC. ${ }^{[17]}$ In a study of 5017 patients with initially benign results who underwent repeat FNAC, thyroid carcinoma were detected in $2.3 \%$ in the initially benign cases at an interval of 6- 12 months. ${ }^{[17]}$ Diffuse, mild to moderate enlargement is seen in Hashimoto's thyroiditis and colloid goiter. Diffuse enlargement with nodularity is seen in multinodular goiter. Solitary enlargement is seen in thyroid cyst, neoplasms and sometimes in nodular goiter with single prominent nodule. On palpation, cases of Hashimoto's thyroiditis were more firm in consistency when compared to other types of thyroid enlargements. Haemorrhagic fluid mixed with colloid aspirate was seen in thyroid cyst in cases associated with secondary hemorrhage in nodular goiter and follicular neoplasm. Maximum number of thyroid enlargement was seen in age group of 21-30 yrs (30.2\%), second highest constituted in 31-40 yrs (19.4\%). Nodular goiter (34) was the most commonest lesion encountered in our study constituting (48 cases, $37.2 \%)$ associated with cystic change (11) and with hyperplasia (3) cases. Maximum number of nodular goiter cases were seen in 31- 40 yrs, one case was seen below 15 yrs and few cases after 45 yrs. The cytological features of nodular goiter observed were abundant thick and thin colloid, follicular cells were few in groups, monolayered sheets and showed variation in cell size. Cases with few cyst macrophages, hemosiderin laden macrophages also observed along with nodular feature were labeled as nodular goiter with cystic change. Presence of increased number of follicular cells with abundant cytoplasm, fire flares were reported as nodular goiter with feature of hyperplasia. Eleven cases $(8.5 \%)$ of nodular goiter showed cystic change, and the aspirate was mainly brownish fluid. three cases of nodular goiter (2.3\%) showed features of hyperplasia. The centrifuged smears of this fluid usually did not show any follicular cells. Only background of colloid and cyst macrophages was seen. Colloid goiter was seen in 13 cases (10.1\%), commonest age group of 21-30 yrs and few cases in 31-50 yrs age group. Microscopy showed moderate amount of thin colloid, benign follicular cells. Thyroid cysts were seen in 10 cases $(7.75 \%)$, and maximum number was in 21-50 yrs age group. Nodular goiter with cystic change and simple cyst are difficult to differentiate on cytology as the microscopic features are almost similar in presence of abundant thin colloid, cyst macrophages and hemosiderin laden macrophages, follicular cells in clumps are more commonly seen in nodular goiter. However in inconclusive cases, USG examination proves to be helpful in categorizing the lesion. Hashimoto's thyroiditis was the second most common lesion encountered in our study constituting 45 cases $(34.9 \%)$ more frequently seen in 31 $40 \mathrm{yrs}$ age group and occurs in the span of 21-50 yrs age group. The incidence seems to reduce after $50 \mathrm{yrs}$. The cytological features are presence of thyroid follicular cells infiltrated by the lymphocytes, Hurthle cell change, occasional multi nucleated giant cells with scant or no colloid in the background. In a study by Shirish Chandanwale et $\mathrm{al},{ }^{[20]}$ a study of 150 cases from Pune showed colloid nodular goiter to be the commonest lesion constituting $65.3 \%$ of the total lesion. Thyroiditis was seen in $12.6 \%$ of cases whereas in our study, nodular colloid goiter was the commonest seen in $26.3 \%$ of cases and increase in incidence in Hashimoto's thyroditis/autoimmune thyroditis $34.9 \%$, was seen associated compared to study in Pune where $12.6 \%$ of autoimmune thyroiditis was identified. $6.75 \%$ malignancy was seen in above study and our study showed $6.20 \%$ (8 cases) of malignancy; one was follicular neoplasm and 6 were papillary carcinoma.

\section{Conclusion}

These findings suggest that the wide range of lesions, both benign and malignant, can be diagnosed by FNAC thus restricting surgery to cases only requiring further histopathological evaluation. Nodular goiter $(26.3 \%)$ is the foremost commonest cause of thyroid enlargement followed by Hashimoto's thyroiditis. The FNAC is very useful and readily available tool for evaluating thyroid nodules with high sensitivity and specificity in picking up benign lesion and excluding the malignant disease. This is very helpful in patient counselling and defining the extent of surgery.

\section{References}

1. Jayaram G. Papillary carcinoma. Atlas and text of thyroid cytology. New Delhi: Arya publications; 2006, p. 35-48.

2. Amrikachi M, Ramzy I, Rubenfeld S, Wheeler TM. Accuracy of fineneedle aspiration of thyroid. Arch Pathol Lab Med 2001;125:484-8. 
3. Cramer H. Fine-needle aspiration cytology of the thyroid: an appraisal. Cancer 2000;25(90):325-9.

4. Clark OH. Fine-needle aspiration biopsy and management of thyroid tumors. Am J Clin Pathol 1997;108(Suppl. 4):S22-5.

5. Ravetto C, Colombo L, Dottorini ME. Usefulness of fine-needle aspiration in the diagnosis of thyroid carcinoma: a retrospective study in 37,895 patients. Cancer 2000;90:357-63.

6. La Rosa GL, Belfiore A, Giuffrida D, Sicurella C, Ippolito O, Russo $\mathrm{G}$, et al. Evaluation of the fine needle aspiration biopsy in the preoperative selection of cold thyroid nodules. Cancer 1991; 67: 2137-41.

7. Bajaj Y, Thompson A. Fine needle aspiration cytology in diagnosis and management of thyroid disease. J Layrngol Oto 2006;120:467-9.

8. Mahar SA, Husain A, Islam N. Fine needle aspiration cytology of thyroid nodule: diagnostic accuracy and pitfalls. J Ayub Med Coll Abbottabad 2006;18(4):26-9.

9. Gharib H. Diffuse nontoxic and multinodular goiter. Curr Ther Endocrinal Metab 1994;5:99-101.

10. Bugis SP, Young JKE, Archibald SD, Chen VS. Diagnostic accuracy of fine needle aspiration cytology verses frozen section in solitary thyroid nodules. Am J Surg 1986;152(4):411-6.

11. Boyd LA, Earnardt RC, Dunn JT, Frierson HF, Hanks JB. Preoperative evaluation and predictive value of fine needle aspiration and frozen section of thyroid nodules. J Am Coll Surg 1998;187(5):494-502.

12. Baloch MN, Ali S, Ansari MA, Maher M. Contribution of Fine needle aspiration cytology in the diagnosis of malignant Thyroid nodules. Pak J Surg 2008;24(1):19-21.

13. Sengupta A, Pal R, Kar S, Zaman FA, Sengupta S, Pal S. Fine needle aspiration cytology as the primary diagnostic tool in thyroid enlargement. J Nat Sc Biol Med 2011; 2: 113-118.

14. Bagga PK, Mahajan NC. Fine needle aspiration cytology of thyroid swellings: How useful and accurate is it? Indian Journal of Cancer 2010; 47:437-42.

15. Esmaili HA, Taghipour H. "Fine-Needle Aspiration in the Diagnosis of Thyroid Diseases: An Appraisal in Our Institution," ISRN Pathology, vol. 2012, Article ID 912728, 4 pages, 2012.

16. Muratli A, Erdogan N, Sevim S, Unal I, Akyuz S. Diagnostic efficacy and importance of fine-needle aspiration cytology of thyroid nodules. J Cytol 2014; 31:73-8

17. Gabalec F, Cáp J, Ryska A, Vasatko T and Ceeová V. Benign fine needle aspiration cytology of thyroid nodule: to repeat or not to repeat? European Journal of Endocrinology 2009; 16: 933-37.

18. Steven R. Bomeli, MD, Shane O, LeBeu, MD, and Robert L Ferris $\mathrm{MD}, \mathrm{PhD}$. Evaluation of a thyroid nodule. Otalaryngol Clin North Am 2010; 43(2):229-38.

19. Rahimi M, Farshchian N, Rezaee E, Shahebrahimi K, and Madani H. To differentiate benign from malignant thyroid nodule comparison of sonography with FNAC findings. Pak J Med Sci 2013; 29(1):77-80.

20. Chandanwale S, Singh N, Kumar H, Pradhan P, Gore C, Rajpal M. Clinicopathological correlation of thyroid nodules. Int $\mathrm{J}$ Pharm Biomed Sci 2012; 3(3): 97-102.

Copyright: (C) the author(s), 2019. It is an open-access article distributed under the terms of the Creative Commons Attribution License (CC BY 4.0), which permits authors to retain ownership of the copyright for their content, and allow anyone to download, reuse, reprint, modify, distribute and/or copy the content as long as the original authors and source are cited.

How to cite this article: Kalim A. Frequency of Thyroid Lesions on Fine Needle Aspiration Cytology in Different Age Groups: A Teaching Hospital-Based Study. Asian J. Med. Res. 2019;8(1):PT01-PT04.

DOI: dx.doi.org/10.21276/ajmr.2019.8.1.PT1 